ORIGINAL ARTICLE

\title{
Diagnostic value of radiography in cases of perinatal death: a population based study
}

\author{
$\varnothing$ E Olsen, A Espeland, H Maartmann-Moe, R S Lachman, K Rosendahl
}

Arch Dis Child Fetal Neonatal Ed 2003;88:F521-F524

See end of article for authors' affiliations

Correspondence to:

Dr Olsen, Great Ormond

Street Hospital for Children

NHS Trust, London WCIN

3JH, UK;

oeol@start.no

Accepted

8 November 2002
Objective: To examine the yield of radiographic abnormalities in a population based set of perinatal deaths, the diagnostic value of whole body postmortem radiographs in the same set, and previous factors that may increase the proportion of useful examinations.

Design: Retrospective population based study.

Setting: A region of Norway.

Patients: All infants from a well defined geographical area who were stillborn or had died soon after birth over an 11 year period $(n=542)$, who had routinely undergone whole body radiography and autopsy. Main outcome measures: (a) Proportion of cases with abnormal radiographic findings. (b) Proportion of abnormal radiographs providing new information that was useful for postmortem diagnosis.

Results: Radiographs were abnormal in $162 / 542$ cases (30\%). These provided new information about, but did not help to confirm, the pathological process leading to death in 14/162 (8.6\%), may have helped to confirm, but not establish, the cause(s) of death in $1 / 162(0.6 \%)$, and were of vital importance for establishing the cause(s) of death in $5 / 162$ (3.1\%). Among infants with external malformations, the proportion of useful radiographs was $12 / 100(12 \%)$, and among the remainder it was $8 / 436(1.8 \%)$, a difference of $10.2 \%$ (95\% confidence interval $3.7 \%$ to $16.7 \%$; data missing for six cases).

Conclusions: The diagnostic value of postmortem radiography in this population based set was low. However, radiographic findings were of vital importance for establishing the cause(s) of death in 5/542 cases $(0.9 \%)$.
$P$ ostmortem examinations of infants who die in the perinatal period are important for establishing the causes of death and likelihood of recurrence. ${ }^{1}$ This is important for family planning and also forms the basis for epidemiological surveillance. In the postmortem diagnostic process, whole body radiography is essential for diagnosing skeletal dysplasias. ${ }^{2}{ }^{3}$ Previous studies of postmortem radiography have reported the yield of abnormal radiographic findings in case series, but not in population based series, and have seldom explicitly assessed the clinical value of the findings. ${ }^{2-7}$ Consequently, the value of radiographic screening is disputed.

Our aims were to $(a)$ examine the yield of radiographic findings in a population based set of perinatal deaths in which routine whole body radiography had been performed, (b) retrospectively assess the value of these findings in establishing the cause(s) of death, based on a clear cut scoring system, and (c) identify previous factors that may increase the likelihood of obtaining a useful score.

\section{SUBJECTS AND METHODS}

Over the study period from January 1988 to December 1998 all perinatal deaths from 16 weeks gestation to one week after birth, except induced abortions on non-medical indications, were routinely autopsied in our institution. Pathologists also radiographed all the infants using a Faxitron apparatus, fine grain films, and a low $\mathrm{kV}$ technique, by a standardised procedure. ${ }^{2}$ Two films were taken in the anteroposterior projection with the infant supine on the film, extremities extended; one film was to depict the axial skeleton, and the other to depict the extremities. A lateral radiograph was also taken with the infant lying on the film in the decubitus position. Paediatric radiologists reported on all the radiographs.
A total of 1024 infants were examined over the study period. We constructed a population based set by including only infants of mothers residing in our local hospital area at the time of perinatal death $(n=542)$. Our hospital has the only maternity clinic and perinatal pathology unit in this area. Inclusion of subjects was based on recordings directly from consecutive autopsy protocols. According to The Medical Birth Registry of Norway, in the same area and time period, there were 777 perinatal deaths, but this figure also included abortions on non-medical indications. Over the study period, three cases from our institution were referred to other hospitals and subsequently, after induced abortion, were autopsied there.

A perinatal pathologist (HM-M) recorded the following information from the autopsy reports: sex, mode of death, main autopsy findings, and final diagnoses. Of the 542 subjects, $200(37 \%)$ were female, $336(62 \%)$ were male, and six $(1 \%)$ were of unknown or uncertain sex. The male to female ratio in our sample was 1.68; the ratio was 1.46 for the whole population of still and live births from 16 to 27 weeks gestation in Norway over the period 1967-1998 (Medical Birth Registry of Norway ${ }^{8}$ ). Of the 542 cases, 389 (72\%) had died in utero, $81(15 \%)$ were induced abortions, 61 (11\%) died in the early neonatal period (within one week of birth), and $11(2.0 \%)$ were unknown. The Medical Birth Registry of Norway, which is based on mandatory reporting, provided the date of the first day of the last menstrual period. Gestational age was calculated as number of days from this date to the date of death. Mean (SD) gestational age was 24.6 (7.6) weeks.

A radiologist (ØEO) reviewed all the radiology reports, recorded detailed radiographic findings, and, when provided, radiological diagnoses. For infants with normal radiographs, we tabulated the final diagnoses. We constructed a system for scoring the diagnostic value of the radiographic examinations 
Table 1 Scoring system for assessment of level of diagnostic usefulness

\begin{tabular}{llll}
\hline Question & & Response & Score \\
\hline Q1 & Radiography provided information not previously appreciated. & No \\
Q2 & If "Yes" to Q1: This information (in part) expressed some abnormality/disease in the fetus/infant. & No & No \\
Q3 & If "Yes" to Q2: This abnormality/disease was part of the process leading to perinatal death. & 1 & No \\
Q4 & If "Yes" to Q3: The radiological evaluation may have helped to confirm the cause(s) of death. & 3 & No \\
Q5 & If "Yes" to Q4: The radiological findings supported the establishment of the cause(s) of death. & 4 \\
Q6 & If "Yes" to Q5: The radiological findings were of vital importance for establishing the cause(s) of death. & No & 5 \\
& & & Yes \\
\hline
\end{tabular}

(table 1). One rater (ØEO) scored each case using all available information. Only cases with abnormal radiographs were scored. These results were tabulated according to the level of usefulness, radiographic findings, and final diagnoses. We calculated the differences in proportions of high (score $\geqslant 3$ ) and low (score $\leqslant 2$ ) level of usefulness between cases categorised on the basis of the following factors: mode of death (intrauterine, induced abortion, or postnatal); presence of external malformations; presence of placenta abnormalities. The 95\% confidence intervals of each of the differences were calculated.

\section{RESULTS}

The radiographs were abnormal in 162/542 cases (30\%). Table 2 lists the number of subjects, radiographic findings, and cause(s) of death for each level of diagnostic usefulness as assessed by our scoring system. Of the 162 radiographic examinations with abnormal findings, 117 (72\%) were thought not to have contributed any new information (level $0), 21(13 \%)$ were thought to have contributed new information without pathological significance (level 1), four $(2.5 \%)$ were thought to have contributed new information that (in part) expressed some fetal abnormality/disease, but was without relevance for the process leading to death (level $2)$, and $14(8.6 \%)$ were thought have to contributed new, relevant information about the process leading to death, but without helping to confirm the cause(s) of death (level 3). Soft tissue calcification was seen on radiographs in eight cases. As shown in table 2, after postmortem examination, the causes of death in these infants were unknown (three cases), amnioplacental abnormalities (three cases), and multiple abnormalities (two cases). We scored all of these as level 3. In $1 / 162(0.6 \%)$, the radiographs provided new information that may have helped to confirm the cause(s) of death, but without definitely supporting the establishment of the diagnosis (level 4), and 5/162 (3.1\%) provided new information of vital importance for establishing the cause(s) of death (level 6). No cases were scored as level 5. All the cases on level 6 had been diagnosed as skeletal dysplasias. For the whole study group, 20/542 (3.7\%) of the radiographic examinations were judged to be on level 3 or above.

Table 3 lists the causes of death among infants judged radiographically normal. Of these, $181 / 380(48 \%)$ died from amnioplacental disease, and 35/380 (9.2\%) were induced abortions. For $90 / 380(24 \%)$, the cause of death remained unknown after autopsy and radiography.

The proportion of radiographic examinations that yielded a usefulness score of 3 or above differed significantly between groups classified according to the presence or not of external malformations (table 4). In the group of infants with external malformations, $12 / 100(12 \%)$ of the radiographic examinations were considered to be level 3 or above, whereas among the cases without external malformations the proportion was $8 / 436$ ( $1.8 \%$ ), giving a difference between the groups of $10.2 \%$ (95\% confidence interval $3.7 \%$ to $16.7 \%$ ). Seven of these eight were judged to be level 3. One was level 4, in which the radiographs showed femoral inflammatory changes, and the cause of death was premature rupture of the fetal membranes.

\section{DISCUSSION}

We found radiographic abnormalities in 30\% of infants who died in the perinatal period and were screened by whole body radiography. Only a few of these abnormal findings were thought to have facilitated the postmortem diagnostic process, although radiographic findings were of vital importance for establishing the cause of death in five of 542 cases $(0.9 \%)$.

Our study was population based, including only cases in which the mother resided in our local hospital area. Both autopsy and radiography had been performed routinely in all cases of perinatal death in this area. As the study institution was the only maternity clinic in this geographical area, bias that could have been caused by referral of complicated cases was minimised. The retrospective nature of the study may, however, limit the data validity, but we believe that they probably represent everyday practice. Missing cases may have caused some inaccuracy, although these were probably abortions on non-medical indications, which had not been examined post mortem. We used scoring criteria for level of diagnostic usefulness that we had developed for this study. The criteria had not been validated, and only one person carried out the scoring. However, we feel that we have justified the use of these criteria by defining clear cut categories and by tabulating the scores as well as the radiographic findings and final diagnoses. A weakness of the study is that we did not attempt to quantify potential benefits of radiographic findings unrelated to the work up of the cause(s) of death.

The reported yields of radiographic abnormalities in cases of perinatal death differ considerably. In a study from the United States, the proportion of abnormalities was $18.5 \%$ in a "largely unselected group".. A review of 2500 routinely examined cases from New Zealand identified $18.2 \%$ abnormal radiographs. ${ }^{3}$ Higher occurrences of abnormality were noted in a Danish $(59 \%)^{5}$ and a Finish study $(68 \%){ }^{2}$ A study from England found skeletal abnormalities in $18 \%$ and soft tissue abnormalities in $21 \%{ }^{6}$ None of these studies were population based. We suspect that the wide variation in values may be partly due to differences in sample selection and reporting of radiographic abnormalities. The significance of such biases cannot be confidently assessed for each of the previously published studies, and real differences in incidence of various abnormalities cannot be ruled out.

The $30 \%$ yield of radiographic abnormalities in our study may seem high for a non-selected group. We speculate that this may, at least partly, be explained by a low perinatal death rate. During the study period, perinatal mortality in our country ranged between 5.8 and 7.9 per 1000 births (Statistics Norway), which is fairly low in a global perspective. A low perinatal death rate probably reflects 
Table 2 Radiographically abnormal findings and final diagnoses of cause of death on different levels of diagnostic usefulness

\begin{tabular}{|c|c|c|c|c|}
\hline Level & $\begin{array}{l}\text { Subjects on } \\
\text { level }\end{array}$ & Radiographic findings & No of subjects & $\begin{array}{l}\text { Final diagnoses of causes of death, and No of subjects with } \\
\text { diagnosis }\end{array}$ \\
\hline \multirow[t]{9}{*}{0} & 117 & Oedema & 18 & $\begin{array}{l}\text { Induced abortion: } 9 \text { (myelomeningocele: } 2 \text {, hydrops foetalis: } 2 \text {, } \\
\text { lymphangioma, cystic: 1, multiple abnormalities: } 1 \text {, hernia, } \\
\text { umbilical: 1, Down's syndrome: 1, growth retardation: 1) } \\
\text { Unknown: } 4 \\
\text { Umbilical cord, abnormality: } 3 \\
\text { Other: } 2 \text { (abruptio placantae: } 1 \text {, Down's syndrome: 1) }\end{array}$ \\
\hline & & Anencephaly & 17 & $\begin{array}{l}\text { Induced abortion: } 15 \text { (anencephaly: } 11 \text {, amniotic band syndrome: } \\
\text { 2, cardiovarcular abnormalities: } 1 \text {, multiple abnormalities: } 1 \text { ) } \\
\text { Multiple abnormalities: } 2\end{array}$ \\
\hline & & Pneumothorax & 16 & $\begin{array}{l}\text { Hyaline membrane disease: } 6 \\
\text { Other: } 10 \text { (diaphragm. hernia: } 1 \text {, infection: } 1 \text {, amniotic bands: } 1 \text {, } \\
\text { fetal membranes, rupture: } 1 \text {, prematurity, abnormalities, other: } 6 \text { ) }\end{array}$ \\
\hline & & Trauma & 14 & $\begin{array}{l}\text { Unknown: } 9 \\
\text { Amnion/placenta, abnormalities: } 3 \\
\text { Induced abortion: } 1 \text { (Dandy-Walker syndrome) } \\
\text { Respiratory system abnormalities: } 1\end{array}$ \\
\hline & & Hand and/or foot deformities & 7 & $\begin{array}{l}\text { Induced abortion: } 5 \text { (myelomeningocele: } 3 \text {, Down's syndrome: } 1 \text {, } \\
\text { multiple abnormalities: } 1 \text { ) } \\
\text { Other: } 2 \text { (hydrops foetalis: 1, multiple abnormalities: } 1 \text { ) }\end{array}$ \\
\hline & & Abnormal thoracic shape & 9 & $\begin{array}{l}\text { Unknown: } 5 \\
\text { Asphyxia: } 2\end{array}$ \\
\hline & & Contractures & 5 & $\begin{array}{l}\text { Other: } 2 \text { (respiratory system abnormalities: 1, trisomy 18: 1) } \\
\text { Induced abortion: } 4 \text { (arthrogryposis: 3, Arnold-Chiari malf.: 1) } \\
\text { Unkown: } 1\end{array}$ \\
\hline & & Myelomeningocele & 4 & $\begin{array}{l}\text { Induced abortion: } 2 \text { (myelomeningocele: } 1 \text {, multiple } \\
\text { abnormalities: } 1 \text { ) } \\
\text { Other: } 2 \text { (Arnold-Chiari malformation: 1, multiple abnormalities: } 1 \text { ) }\end{array}$ \\
\hline & & $\begin{array}{l}\text { Other (macrocephalus, microcephalus, } \\
\text { contractures, post fossa abnormalities, } \\
\text { calcifications, rib abnormalities) }\end{array}$ & 27 & \\
\hline \multirow[t]{2}{*}{1} & 21 & Abnormal number or shape of rib(s) & 12 & $\begin{array}{l}\text { Amnion/placenta, abnormalities: } 4 \\
\text { Unknown: } 3 \\
\text { Induced abortion: } 2 \text { (Down's syndrome: 1, multiple abnormal.: 1) } \\
\text { Other: } 3 \text { (muscular dystrophia: 1, abortion, missed: 1, urogenital } \\
\text { abnormalities: 1) }\end{array}$ \\
\hline & & $\begin{array}{l}\text { Other (spinal or pelvic abnormalities, } \\
\text { gass collections) }\end{array}$ & 9 & \\
\hline 2 & 4 & $\begin{array}{l}\text { Other (spinal, thoracic shape or long } \\
\text { bones abnormalities) }\end{array}$ & 4 & \\
\hline \multirow[t]{2}{*}{3} & 14 & Soft tissue calcifications & 8 & $\begin{array}{l}\text { Unknown: } 3 \\
\text { Amnion/placenta, abnormalities: } 3 \\
\text { Mulitple abnormalities: } 2\end{array}$ \\
\hline & & $\begin{array}{l}\text { Other (foot deformities, multiple } \\
\text { abnormalities) }\end{array}$ & 6 & \\
\hline 4 & 1 & Inflammatory changes in femur & 1 & Fetal membranes, premature rupture: 1 \\
\hline 5 & 0 & & & \\
\hline 6 & 5 & $\begin{array}{l}\text { Asphyxiating thoracic dysplasia } \\
\text { Lethal multiple pterygium syndrome } \\
\text { Osteogenesis imperfecta } \\
\text { Thanatophoric dysplasia }\end{array}$ & $\begin{array}{l}2 \\
1 \\
1\end{array}$ & $\begin{array}{l}\text { Asphyxiating thoracic dysplasia: } 2 \\
\text { Lethal multiple pterygium syndrome: } 1 \\
\text { Osteogenesis imperfecta: } 1 \\
\text { Thanatophoric dysplasia: } 1\end{array}$ \\
\hline Sum & 162 & & 162 & \\
\hline
\end{tabular}

Assessment was according to table 1.

relatively successful perinatal care. Consequently, the occurrence and severity of abnormal findings among those who die despite this could be expected to be high.

The efficacy of postmortem perinatal radiography has been assessed on the basis of its yield of normal and abnormal findings. ${ }^{467}$ Ideally, the next step would be to assess the efficacy of its diagnostic accuracy against an independent diagnostic "gold standard". ${ }^{9}$ However, such diagnostic "gold standards" are not readily available, and in some cases-for example, skeletal dysplasia-radiography itself provides a final diagnosis. In other cases, a final diagnosis cannot be established by any available method. We therefore assessed the next level of efficacy, that of diagnostic thinking, which reflects the impact of test results on diagnostic reasoning, ${ }^{9}$ and combined this with another useful approach, analysis of other factors to identify predictors of useful radiological test results. ${ }^{10}$
The basis for our assessment was that a radiograph was considered useful only if it provided information that was not previously available-for example, from clinical examination or autopsy. We found that only 20 (3.7\%) of all the radiographic examinations were on usefulness level 3 or above based on our scoring system. However, we only scored cases with abnormal radiographs, even though normal radiographs may also have been diagnostically helpful in some cases. Hypothetically, this would be the situation if the examination were normal in an infant with a high probability for skeletal abnormalities-for example, antenatal ultrasound findings or a known genetic predisposition. The real diagnostic value may therefore be higher than our estimate.

It has been suggested that radiography may help in the assessment of intrauterine growth restriction. ${ }^{11}$ Two recent papers showed that skeletal growth stage-that is, bone length, presence of ossification centres, and the relation 
Table 3 Cause of death among 380 infants judged radiographically normal

\begin{tabular}{ll}
\hline Placenta disease and premature rupture of fetal & 181 \\
membranes & \\
Unknown & 90 \\
Induced abortions & (total 35) \\
Multiple abnormalities & 4 \\
Myelomeningocele & 4 \\
Maternal disease & 3 \\
Trisomy 21 & 3 \\
Cystic adenomatoid malformation of lung & 2 \\
Information missing & 2 \\
Nervous system malformations, other & 2 \\
Oligohydramnios and urogenital abnormalities & 2 \\
Trisomy 18 & 2 \\
46, XY, la+ with multiple abnormalities & 1 \\
Amniotic band syndrome & 1 \\
Arnold-Chiari malformation & 1 \\
Cardiovascular abnormalities & 1 \\
Dandy-Walker syndrome & 1 \\
Hydrocephalus & 1 \\
Infectious pregnancy complication & 1 \\
Mucopolysaccharidosis type II & 1 \\
Polycystic kidneys disease & 1 \\
Trisomy 13 & 1 \\
Urogenital abnormalities, other & 1 \\
Asphyxia, hyaline membrane disease and dysmaturity & 27 \\
Infectious disease complicating pregnancy, or infant & 7 \\
infection & \\
Maternal diseases or other maternal factors & 7 \\
Fetofetal transfusion & 6 \\
Cardiovascular abnormalities & 5 \\
Hydrops foetalis & 5 \\
Intracranial haemorrhages & 3 \\
Multiple abnormalities & 3 \\
Abortion, missed & 2 \\
Other & \\
Sum & \\
\hline
\end{tabular}

between length and ossification stage-are probably reflections of the overall fetal size (weight) and probably not specifically influenced by intrauterine growth restriction. ${ }^{12}{ }^{13}$ We therefore consider it unlikely that radiography has a potential role in ascertaining a "true gestational age" or the presence of growth restriction, even though it is important for assessing the relative measurements of individual bones, used in diagnosing skeletal dysplasias.

Guidelines for the use of perinatal postmortem radiography have been proposed, but most studies have based their recommendations solely on the rate of abnormal findings. However, on the basis of these results, we are not able to recommend any specific criteria for selecting cases in which postmortem radiography would be useful. A comparison with our results would be difficult because the criteria for this assessment were not given. On the basis of our data, if we had used radiography only in cases with external malformations, the number of radiographic examinations could have been reduced from 536 to 100 (81\% reduction). In so doing we would have missed seven cases scored at usefulness level 3, in which the radiographic findings probably had little effect on the diagnostic process (five with abdominal calcifications, one with forefoot abduction deformity, and one with possible increased density of the skeleton). We would also have missed one case scored at level 4, in which the radiographs showed inflammatory changes in the skeleton and the final diagnosis was premature rupture of the fetal membranes. In the last case, the radiographs may have helped to confirm the autopsy diagnosis. However, from these results, we cannot recommend any criteria for selection for radiography. There is
Table 4 Proportions of radiographic examinations scored as useful (level 3 or higher), grouped by various predictive factors

\begin{tabular}{|c|c|c|c|}
\hline & Rated useful & Percentage & $\begin{array}{l}\text { Difference ( } 95 \% \\
\text { confidence interval) }\end{array}$ \\
\hline \multicolumn{4}{|l|}{ Mode of death* } \\
\hline Prenatal death & $11 / 389$ & 2.8 & $2.1 \%(-1.8$ to 6.0$) \dagger$ \\
\hline Induced abortion & $6 / 81$ & 7.4 & $4.7 \%(-1.2$ to 10.6$) \dagger$ \\
\hline $\begin{array}{l}\text { Early neonatal death } \\
\text { Placenta findings } ¥\end{array}$ & $1 / 61$ & 1.6 & $2.0 \%(-1.6$ to 5.6$) \dagger$ \\
\hline Any abnormality & $15 / 396$ & 3.8 & \\
\hline Normal & $5 / 106$ & 4.7 & $0.9 \%(-3.5$ to 5.4$)$ \\
\hline \multicolumn{4}{|l|}{$\begin{array}{l}\text { External } \\
\text { malformations§ }\end{array}$} \\
\hline OYes & $12 / 100$ & 12 & \\
\hline No & $8 / 436$ & 1.8 & $10.2 \%$ (3.7 to 16.7$)$ \\
\hline
\end{tabular}

*Data missing for 11 cases.

†Compared with other two groups combined.

tData missing for 40 cases.

$\S$ Data missing for six cases.

minimal inconvenience in radiographing these infants, and protection against radiation is not an issue. Furthermore, our results may not reflect the full range of potential benefits that could be gained from normal and abnormal radiographs.

\section{ACKNOWLEDGEMENTS}

Haakon and Sigrun Ødegaard's Foundation contributed financially to the study.

Preliminary results of this study were presented at the Congress of The European Society for Paediatric Radiology, Jerusalem, 1999.

\section{Authors' affiliations}

$\varnothing \mathrm{E}$ Olsen, A Espeland, K Rosendahl, Department of Radiology, Haukeland University Hospital, Bergen, Norway

A Espeland, K Rosendahl, Section of Radiology, Department of Surgery, University of Bergen Medical School

H Maartmann-Moe, Department of Pathology, Haukeland University Hospital

R S Lachman, International Skeletal Dysplasia Registry, Cedars-Sinai Medical Center, Los Angeles CA, USA

\section{REFERENCES}

1 Mueller RF, Sybert VP, Johnson J, et al. Evaluation of a protocol for postmortem examination of stillbirths. N Engl J Med 1983;309:586-90.

2 Seppanen U. The value of perinatal post-mortem radiography. Experience of 51 4 cases. Ann Clin Res 1985:17:S1-59.

3 Foote GA, Wilson AJ, Stewart JH. Perinatal post-mortem radiography: experience with 2500 cases. Br J Radiol 1978;51:351-6.

4 Griscom NT, Driscoll SG. Radiography of stillborn fetuses and infants dying at birth. AJR Am J Roentgenol 1980:134:485-9.

5 Gronvall J, Graem N. Radiography in post-mortem examinations of fetuses and neonates. Findings on plain films and at arteriography. APMIS 1989;97:274-80.

6 Winter RM, Sandin BM, Mitchell RA, et al. The radiology of stillbirths and neonatal deaths. Br J Obstet Gynaecol 1984;91:762-5.

7 Cremin BJ, Draper R. The value of radiography in perinatal deaths. Pediatr Radiol 1981;11:143-6.

8 Skjaerven R, Gjessing HK, Bakketeig LS. Birthweight by gestational age in Norway. Acta Obstet Gynecol Scand 2000;79:440-9.

9 Thornbury JR. Clinical efficacy of diagnostic imaging: love it or leave it. AJR Am J Roentgenol 1994;162:1-8.

10 Reinus WR. Expanding the sphere of outcomes of research in radiology. Radiology 1997;203:13-5.

11 Stempfle N, Huten Y, Fondacci C, et al. Fetal bone age revisited: proposal of a new radiographic score. Pediatr Radiol 1995;25:551-5.

12 Olsen ØE, Lie RT, Maartmann-Moe H, et al. Skeletal measurements among infants who die during the perinatal period: new population-based reference. Pediatr Radiol 2002;32:667-73.

13 Olsen ØE, Lie RT, Lachman RS, et al. Ossification sequence in infants who die during the perinatal period: population-based references. Radiology 2002;225:240-4. 